OPEN ACCESS

Edited by: Deseada Parejo,

University of Extremadura, Spain

Reviewed by:

Jiri Reif,

Charles University, Czechia

Huijie Qiao,

Institute of Zoology, Chinese

Academy of Sciences (CAS), China

*Correspondence:

Emilio Pagani-Núñez

emilio.pnunez@xjtlu.edu.cn

Wen Bo Liao

liaobo_0_0@126.com

Junhua Hu

hujh@cib.ac.cn

${ }^{\dagger}$ These authors have contributed equally to this work

Specialty section:

This article was submitted to Behavioral and Evolutionary Ecology,

a section of the journal

Frontiers in Ecology and Evolution

Received: 21 August 2020 Accepted: 30 November 2020

Published: 21 December 2020

Citation:

Liang D, Yang S, Pagani-Núñez E, He C, Liu Y, Goodale E, Liao WB and

Hu J (2020) How to Become a Generalist Species? Individual Niche Variation Across Habitat

Transformation Gradients.

Front. Ecol. Evol. 8:597450. doi: 10.3389/fevo.2020.597450

\section{How to Become a Generalist Species? Individual Niche Variation Across Habitat Transformation Gradients}

\author{
Dan Liang ${ }^{1,2 \dagger}$, Shengnan Yang ${ }^{3 \dagger}$, Emilio Pagani-Núñez ${ }^{4 \star}$, Chao He ${ }^{5}$, Yang Liu ${ }^{1}$, \\ Eben Goodale ${ }^{5}$, Wen Bo Liao ${ }^{6 *}$ and Junhua $\mathrm{Hu}^{3 *}$
}

' State Key Laboratory of Biocontrol, School of Ecology/School of Life Sciences, Sun Yat-sen University, Guangzhou, China, ${ }^{2}$ Princeton School of Public and International Affairs, Princeton University, Princeton, NJ, United States, ${ }^{3}$ Chengdu Institute of Biology, Chinese Academy of Sciences, Chengdu, China, ${ }^{4}$ Department of Health and Environmental Sciences, Xi'an Jiaotong-Liverpool University, Suzhou, China, ${ }^{5}$ Guangxi Key Laboratory of Forest Ecology and Conservation, College of Forestry, Guangxi University, Nanning, China, ${ }^{6}$ Key Laboratory of Southwest China Wildlife Resources Conservation (Ministry of Education), China West Normal University, Nanchong, China

Species in transformed habitats, frequently labeled as environmental generalists, tend to show broader niches than species in natural habitats. However, how population niche expansion translates into changes in the niches of individual organisms remains unclear, particularly in the context of habitat transformation. Niche expansion could be a product of individuals having broader niches, greater distances among individuals' niches, or a combination of both processes. This would challenge the traditional conceptions on niche dynamics, which emphasize the role played by individual specialization (IS). Here, using stable isotopes, we computed total niche width (TNW), its within- and betweenindividual components (WIC and $\mathrm{BIC}$ ), and IS (the ratio WIC/TNW), in 13 populations of 6 bird species and 8 populations of 3 frog species in natural and transformed habitats. We confirmed that species had broader niche width in transformed than in natural habitats, yet population niche expansion across habitats was mainly a product of increased distance between individuals. Within each habitat type, increases in TNW were linked to increases in WIC for all habitat types, while relationships between TNW and BIC were found in transformed but not in natural habitats. Hence, both increased individual niche width and increased distance among individuals were apparent within habitats, particularly in transformed ones, where increases in WIC dominated. Neither across or within habitats was niche expansion associated with increasing IS. Therefore, our results overturn traditional conceptions associated with the niche variation hypothesis and illustrate that niche expansion is not invariably associated with increased IS, because the distance between individual's niches $(\mathrm{BIC})$ can increase, as well as the breadth of those niches (WIC).

Keywords: habitat transformation, individual specialization, niche variation hypothesis, urbanization, stable isotopes 


\section{INTRODUCTION}

Habitat transformation is one of the main drivers of biodiversity loss (Newbold et al., 2015). This loss is not neutral in that predominantly specialized species - those requiring particular habitat or food resources - are disproportionately lost, while environmental generalists - those with less selective habitat or dietary needs - become dominant (Flynn et al., 2009; Ducatez et al., 2018; Sol et al., 2020). A consequence of this process is that species in transformed habitats display broader niches than species in natural habitats (Bonier et al., 2007; Clavel et al., 2011; Coogan et al., 2018; Pagani-Núñez et al., 2019; Palacio, 2019). It is unclear however how this process of population niche expansion translates into the niches of the individual organisms.

Total niche width (TNW) of a population is composed by the sum of its within-individual component (WIC) and betweenindividual component (BIC) (Roughgarden, 1972, 1974), while individual specialization (IS) is computed as the ratio between WIC and TNW (Bolnick et al., 2003; Araújo et al., 2011), and increases as this ratio decreases. Traditionally, the niche variation hypothesis $(\mathrm{NVH})$ predicts that TNW is positively correlated with IS (Van Valen, 1965), meaning that increases in TNW are mostly associated with increasing IS (Cachera et al., 2017; Maldonado et al., 2017). This is because when TNW increases, IS is likely to increase too, simply because TNW would increase at a higher rate than WIC. This seems a realistic assumption, as generalist populations are often composed of individuals only using a subset of the total population niche (Araújo et al., 2011; Layman et al., 2015; Pagani-Núñez et al., 2015).

Many studies, however, have cricitized and/or found no support to the NVH (e.g., Simberloff et al., 2000; Meiri et al., 2005). This suggests that population niche expansion could be achieved through different mechanisms than an increase in IS, such as changes in other components of individuals' niches or a population's niche structure. As stated above, when a population niche expands (TNW increases), the value of the ratio WIC/TNW decreases automatically, as long as WIC does not necessarily change, or at least that it increases less than TNW and thus the main increase is in BIC (because TNW = BIC + WIC). We suggest here that if TNW increases the components of TNW likely increase too, yet this process of niche expansion could be achieved in many different ways (either BIC, WIC or both may increase). It is thus fundamental to consider how changes in these different niche components shape patterns of niche expansion, and habitat transformation gradients offer an excellent scenario to test these ideas.

Increases in both WIC and BIC are likely to occur across transformation gradients. Assuming that population size stays constant, this process of niche expansion at the population level (i.e., increasing TNW) could be reflected at the individual level through three main avenues: increasing WIC, increasing BIC, or increasing both WIC and BIC (Figure 1). Several extrinsic and intrinsic factors could facilitate this process. For instance, habitat heterogeneity could promote greater BIC -less overlap among individuals (Darimont et al., 2009; Newsome et al., 2015). Conversely, innovativeness could promote greater WIC -larger individual niches (Sol et al., 2013; Ducatez et al.,
2015). Furthermore, these processes may also be apparent within habitats -particularly transformed ones- as WIC and BIC may increase with increasing population niches.

In this study, we assessed the role played by different niche components (WIC, BIC and the ratio WIC/TNW) in explaining patterns of niche expansion across habitat transformation gradients. We did this using six bird and three frog species inhabiting natural, rural and urban habitats in China, which harbors tremendous biodiversity yet is currently experiencing a vast process of habitat transformation driven particularly by urbanization (Seto et al., 2011; Liu et al., 2018). Birds and frogs strongly respond to habitat transformation and human activities, and are commonly used as models to investigate this issues (McKinney, 2008; Herrera-Montes and Aide, 2011). Furthermore, there is a wealth of research using stable isotopes to answer different questions about these two taxa (e.g., Inger and Bearhop, 2008; Araújo et al., 2009; Smith et al., 2017). While birds and frogs certainly are different (frogs would be less mobile and to some extent more specialized than birds, at least in relation to habitat use, due to their dependency from water) (e.g., Dayananda et al., 2017), we confirmed the consistency of our hypotheses by pooling together data from both taxa. To compute niche characteristics we used stable isotopes, which has become a common technique to quantify trophic niche (Layman et al., 2012; Figgener et al., 2019). First, we asked if species had broader niches in transformed than in natural habitats, and determined whether differences in WIC, BIC and the ratio WIC/TNW existed across natural, rural and urban habitats. Second, we assessed the relationships between these niche components and TNW within habitats. In doing so, we were able to determine which of these individual niche components was most important in explaining population niche expansion (Figure 1).

\section{MATERIALS AND METHODS}

\section{Study Locations and Species}

We passively sampled passerines from November 2015 to April 2017 using mist nets in six locations in Guangxi Zhuang Autonomous Region and Yunnan Province (southwest China), and frogs during July-August 2018, actively capturing them in six locations in Gansu and Shaanxi Provinces (northwest China) (Figure 2 and Supplementary Material 1). We categorized our study locations as urban, rural and natural habitats, according to land-use gradients and the level of anthropogenic disturbance (cf. Newbold et al., 2015). Natural habitats were relatively undisturbed and protected forested areas, rural habitats were predominantly agricultural areas or managed forests with low human population density, and urban habitats were humandominated areas inside cities (Liang et al., 2018; Pagani-Núñez et al., 2019; Figure 2). Six common passerines in the area included the Rufous-capped Babbler Stachyris ruficeps, the Gray-checked Fulvetta Alcippe morrisonia, the Common Tailorbird Orthotomus sutorius, the Red-whisked Bulbul Pycnonotus jocosus, the Redbilled Leiothrix Leiothrix lutea and the Scaly-breasted Munia Lonchura punctulata. Frogs belonged to three species of the genus Feirana (Swelled-vented Frog F. quadranus, Taihangshan 

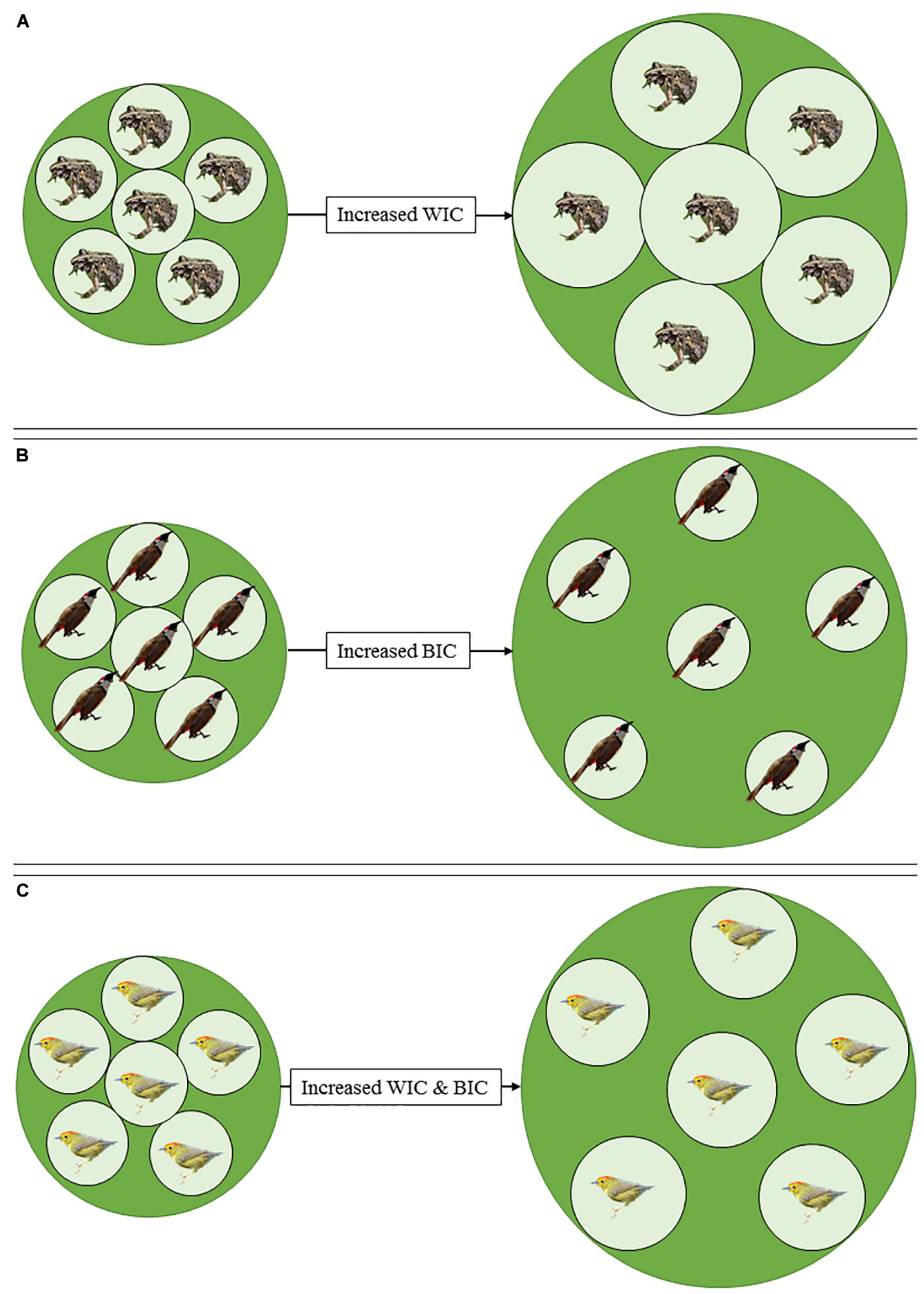

FIGURE 1 | Conceptual illustration of population-level niche expansion resulting from different individual-level niche changes. When population size remains constant, population niche expansion could be achieved through: (A) increased within-individual niche component (WIC), (B) increased between-individual niche component $(\mathrm{BIC})$, or (C) a combination of both processes. Note that increases in individual specialization (IS = WIC/TNW) may or may not be achieved in all these scenarios.

Swelled-vented Frog F. taihangnica and Kangxian Swelled-vented Frog F. kangxianensis) (Figure 3; Fei et al., 2009; Yang et al., 2011). For birds, we sampled a large number of individuals and species (see Pagani-Núñez et al., 2019). We focused, however, on six common species that were present in several habitats and limited sample size to 10 individuals per species (Figure 3). We did this by randomly selecting up to 10 individuals per species for stable isotope analysis. In doing so, we were able to use 

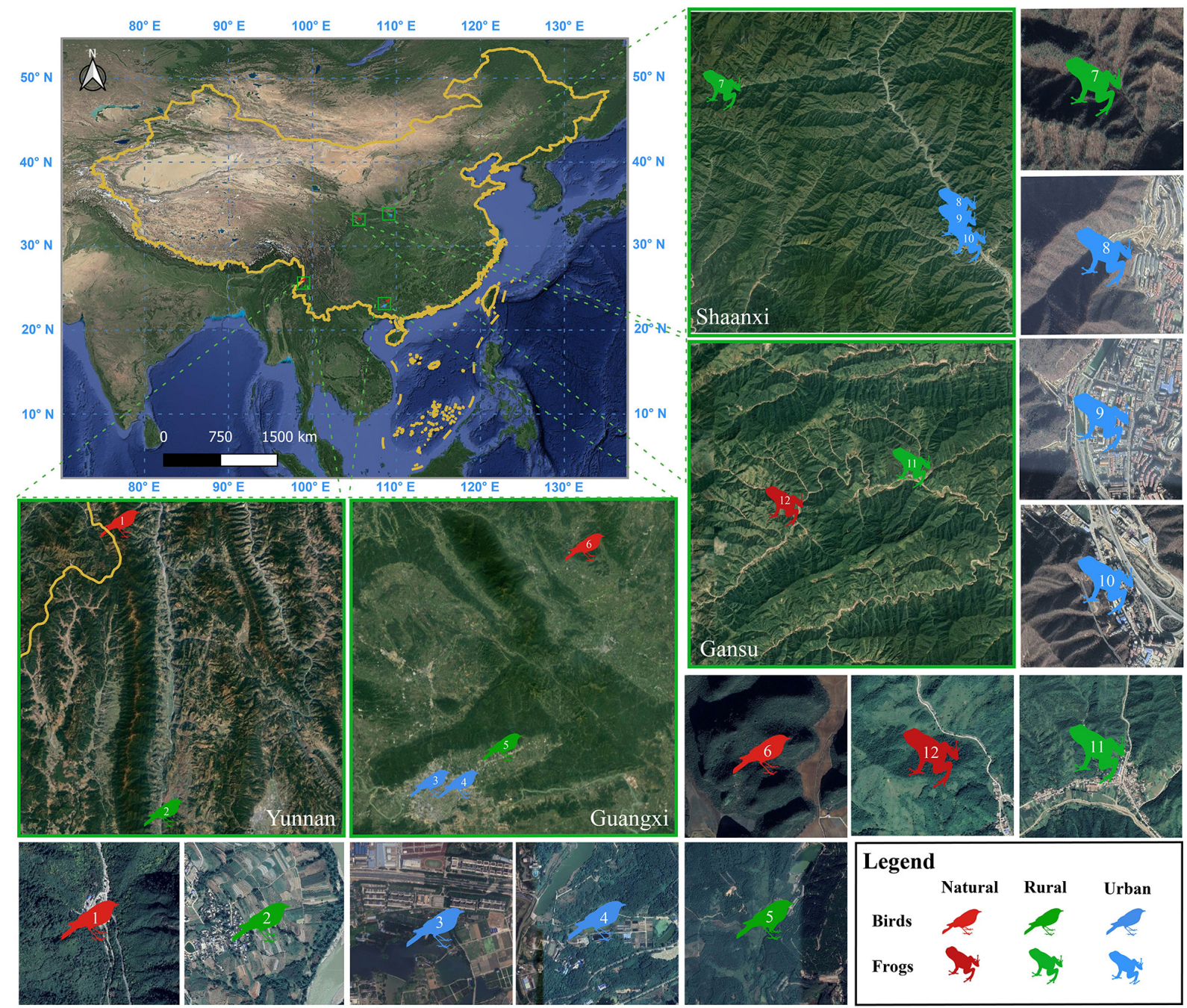

FIGURE 2 | Map showing our study locations in Guangxi Zhuang Autonomous Region and Yunnan Province (southwest China), and Gansu and Shaanxi Provinces (northwest China). Left top panel shows a general map of the People's Republic of China. The four larger squares illustrate the distance among study locations and their general aspect. The smaller squares provide a closer look of these study locations.

a similar number of individuals per species to compute niche characteristics. For frogs, since sample size per species was rather similar but lower in total than for birds, we did not set any sample size threshold. In the end, we used 176 individuals (118 birds and 58 frogs) from 21 populations (Supplementary Material 2).

\section{Sampling Procedures}

After birds were extracted from the mist net, we measured body mass using an electronic balance with an accuracy of $0.01 \mathrm{~g}$. We then collected the second secondary feather (P8) of the right wing and the claw tip of the largest claw from the right leg. All individuals were banded before being released and we only included data from the first capture.

We searched for frogs shortly after sunset in and around water bodies using flashlights. For each captured adult, we measured body mass to the nearest $0.01 \mathrm{~g}$ with an electronic balance. After euthanasia, we clipped the fourth toe for molecular identification and collagen extraction. We also collected the muscle tissue from hind limbs, washed the muscles with distilled water and stored them in $2 \mathrm{ml}$ tubes. All the samples were kept in cold conditions in the field and then stored at $-20^{\circ} \mathrm{C}$ in the laboratory. After sampling, the adult frogs were placed in $4 \%$ buffered formalin and the voucher specimens were deposited in the Herpetological Museum of the Chengdu Institute of Biology (CIB), Chinese Academy of Sciences (CAS). These procedures are part of a long-term line of research focused on the ecology and evolution of Feirana frogs (e.g., Hu and Jiang, 2018; Wang et al., 2019; Huang et al., 2020), and are a common practice in other stable isotope studies on this taxon (e.g., Araújo et al., 2009). For frog species identification, we integratedly referred to morphological characteristics, and geographic and genetic information ( $\mathrm{Hu}$ and Jiang, 2018; Wang et al., 2019; Huang et al., 2020).

All animal handling and processing were in accordance with the Law of the People's Republic of China on the Protection of 


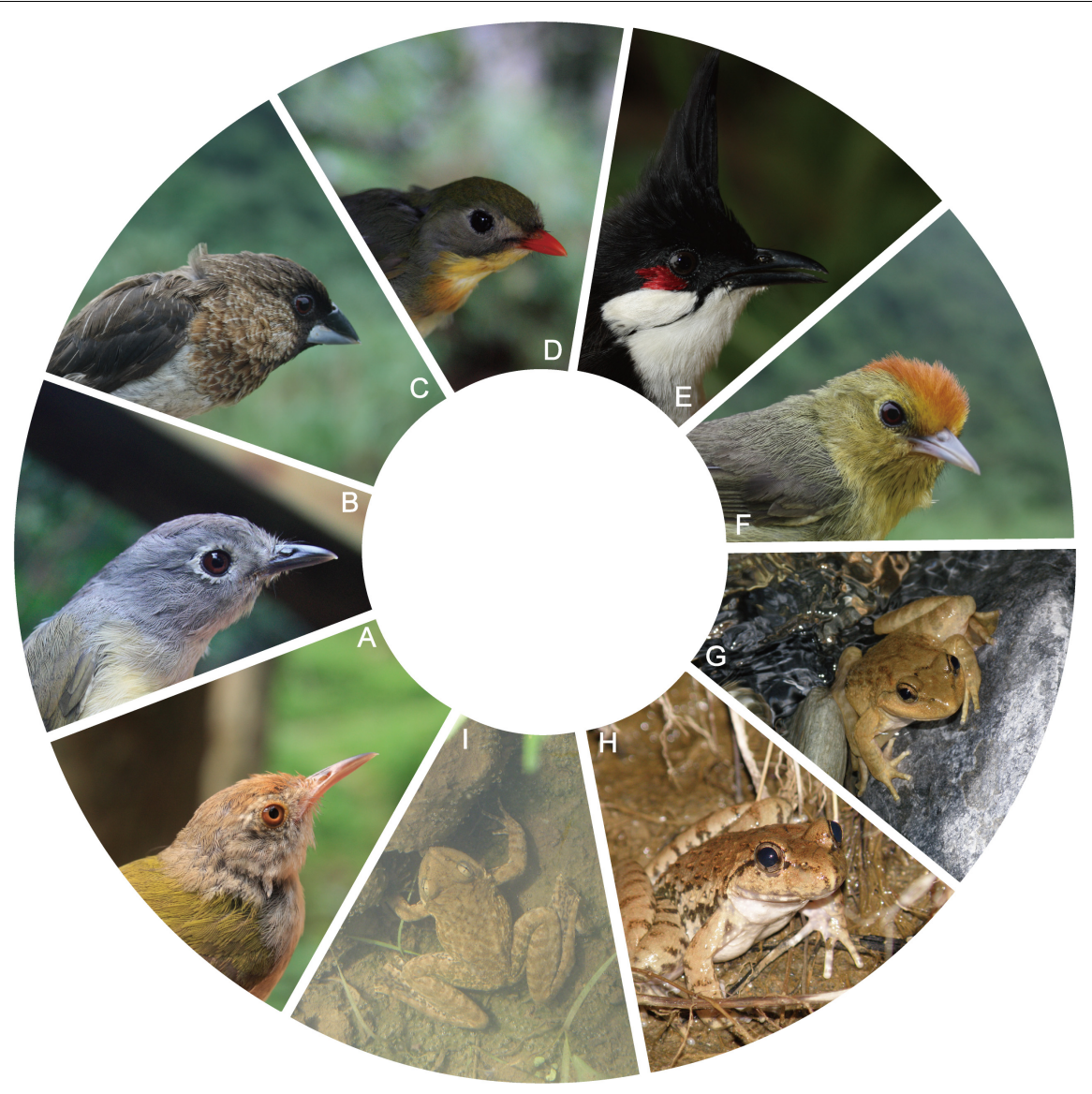

A. Orthotomus sutorius

B. Alcippe morrisonia

C. Lonchura punctulata

D. Leiothrix lutea

E. Pycnonotus jocosus

F. Stachyris ruficeps

G. Feirana kangxianensis

H. Feirana quadranus

I. Feirana taihangnica

FIGURE 3 | Study species including six common passerines from southwest China (Common Tailorbird Orthotomus sutorius, Gray-checked Fulvetta Alcippe morrisonia, Scaly-breasted Munia Lonchura punctulata, Red-billed Leiothrix Leiothrix lutea, Red-whiskered Bulbul Pycnonotus jocosus, and Rufous-capped Babbler Stachyris ruficeps) and three frog species from northwest China (Kangxian Swelled-vented Frog Feirana kangxianensis, Swelled-vented Frog F. quadranus and Taihangshan Swelled-vented Frog F. taihangnica).

Wildlife and approved by the Guangxi Forestry Bureau and the Animal Care Committee of CIB, CAS.

\section{Tissues and Niches}

Nitrogen stable isotope ratios $\left(\delta^{15} \mathrm{~N}\right)$ are commonly used to estimate species' trophic level (Boecklen et al., 2011; Layman et al., 2012). We focused only on this element because we were particularly interested in linking our finding to individuals' and species diets. Using different tissues it is possible to determine individual specialization because different tissues reflect individuals' diets across different temporal scales (Vander Zanden et al., 2015; Bond et al., 2016; Maldonado et al., 2017). Thus, we were able to compute intra-individual niche variation using $\delta^{15} \mathrm{~N}$ values of two easy-to-obtain tissues.

We collected feathers and claws (birds) and muscle and bone collagen samples (frogs) to compute niche characteristics because these tissues provide information on niche use at two different temporal scales for each individual. Feathers correspond to a specific temporal window during summer molt, while claws correspond to the previous weeks to months prior to sample collection (Bearhop et al., 2003; Hahn et al., 2014; Vander Zanden et al., 2015; Bond et al., 2016). We collected these samples continuously across our study period so that they represent diets across a broad temporal scale. Similarly, muscle tissue would reflect niche use in a time window of weeks prior to sample collection, while bone collagen tissue would reflect a broader time span across individuals' development (Vander Zanden et al., 2015; Matsubayashi et al., 2017).

Thus, we used $\delta^{15} \mathrm{~N}$ values from two different tissues from each individual as the continuous data input about niche use to calculate TNW, WIC, BIC and WIC/TNW for each species per location. WIC/TNW ranges from 0 (individuals use completely different resources, i.e., display high IS) to 1 (individuals use the full range of the population niche, i.e., display low IS). In our sample, WIC ranged between 0.04 and 1.13, BIC between 0.05 and 1.62, and TNW between 0.15 and 2.53 (Supplementary Material 2).

\section{Stable Isotope Analysis}

Claws and feathers from birds were cleaned from surface contaminants using $\mathrm{NaOH}(0.25 \mathrm{~mol} / \mathrm{L})$, and then were airdried for at least $12 \mathrm{~h}$. We included approximately $0.35 \mathrm{mg}$ 

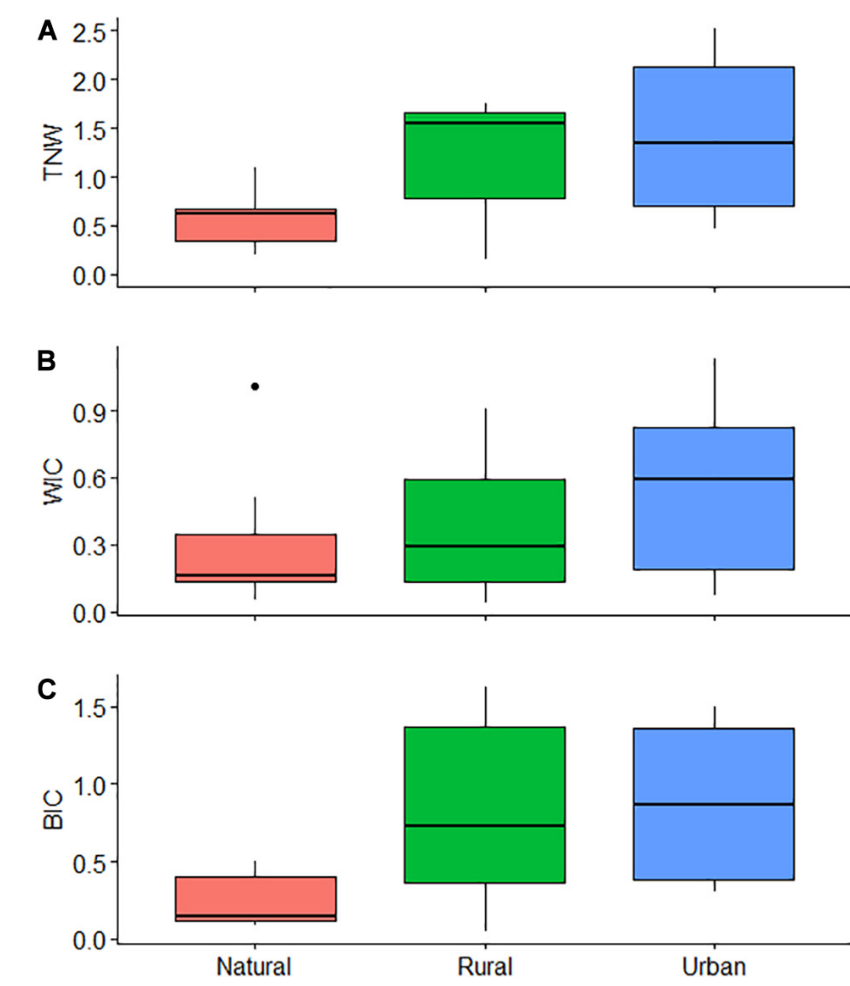
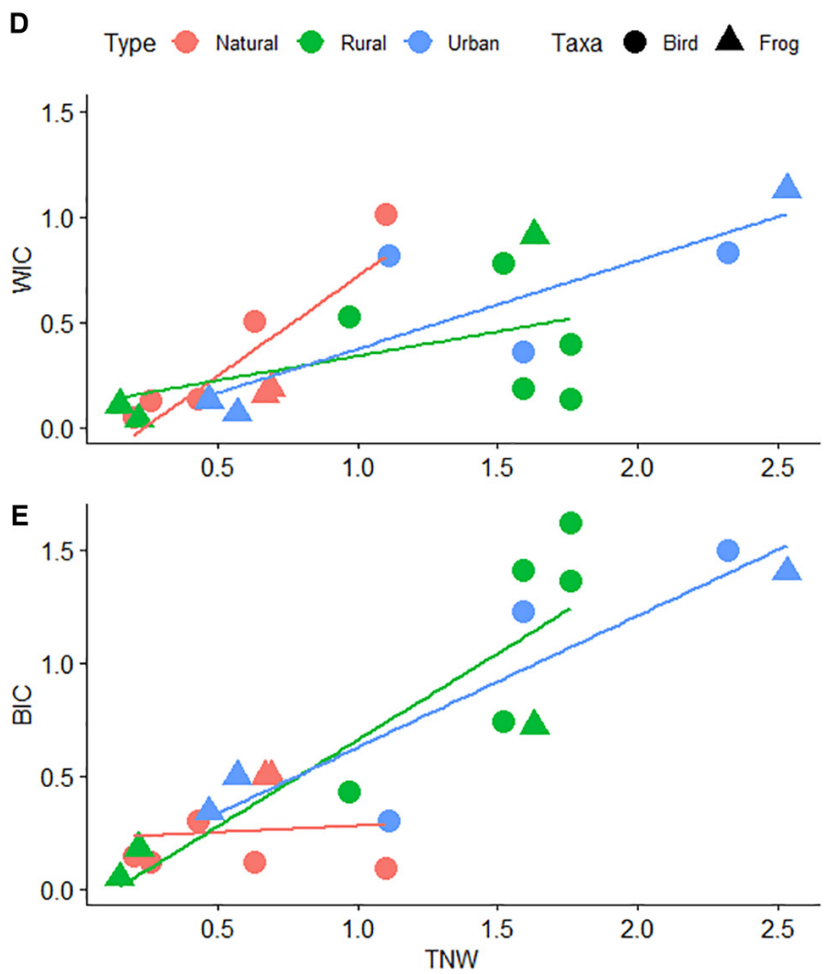

FIGURE 4 | Differences in niche components and their relationshisp across and within habitats. (A) Differences in Total (i.e., population) Niche Width (TNW; $y$-axis) between natural, rural and urban habitats ( $x$-axis). (B) Differences in the Within-Individuals niche Component (WIC; $y$-axis) between natural, rural and urban habitats ( $x$-axis). (C) Differences in the Between-Individuals niche Component (BIC; $y$-axis) between natural, rural and urban habitats ( $x$-axis). (D) Linear relationships between the Within-Individuals niche Component (WIC; $y$-axis) and TNW (x-axis) in natural, rural and urban habitats. (E) Linear relationships between the BIC ( $y$-axis) and TNW ( $x$-axis) in natural, rural and urban habitats.

of feather tips and claws of each individual into separate tin cups, which were loaded for $\delta^{15} \mathrm{~N}$ analyses. We used a Flash 2000 HT elemental analyzer coupled via ConFlo IV Universal Continuous Flow Interface (Thermo Scientific) to a Thermo Scientific DELTA V Advantage isotope ratio mass spectrometer (Thermo Fisher Scientific, Bremen, Germany). We conducted stable isotope analyses for this taxon in the Stable Isotope Laboratory of the College of Forestry at Guangxi University (Nanning, S China). Toe clips from frogs were demineralized for $24 \mathrm{~h}$ in $0.5 \mathrm{M} \mathrm{HCl}$, rinsed twice with deionized water. Next, the samples were treated with $0.1 \mathrm{M} \mathrm{NaOH}$ for $12 \mathrm{~h}$ and washed twice with deionized water. We immersed the bones in a methanol:chloroform mixture (2:1, vol:vol) for about $24 \mathrm{~h}$, then thoroughly rinsed and heated in deionized water at $90^{\circ} \mathrm{C}$ for about $12 \mathrm{~h}$. Bone collagen and muscle tissues from frogs were freeze-dried for $36 \mathrm{~h}$ to constant weight, grounded to a fine powder and analyzed at the Public Center of Experimental Technology in CIB, CAS. We used a vario isotope cube elemental analyzer (vario ISOTOPE cube, Elementar, Germany) interfaced to an isotope ratio mass spectrometer (IsoPrime100, Isoprime, United Kingdom).

For both taxa, stable isotope ratios were expressed as parts per thousand $(\% 0)$ using the equation as follow: $\delta^{15} \mathrm{~N}$ $(\% 0)=[($ Rsample/Rstandard $)-1] \times 1000$, where Rsample and Rstandard are the ${ }^{15} \mathrm{~N}^{/ 14} \mathrm{~N}$ ratios of sample and standard, respectively. The standard was atmospheric nitrogen (AIR $\mathrm{N}_{2}$ ) and measurement precision was $0.25 \%$.

\section{Statistical Analysis}

Using a linear mixed-effects model, we first tested whether TNW was larger in rural and urban habitats than in natural ones. TNW was our response variable, and habitat type (natural, rural or urban), taxa (bird or frog) and species' average body mass were our predictors. We included body mass as it may have played a relevant role in shaping niche community structure and due to the differences between the studied taxa (Vergnon et al., 2009). Study location (Supplementary Material 1) and species (Figure 3 and Supplementary Material 2) were the random factors. Using the same statistical approach, we were interested in determining whether differences in BIC, WIC and IS (the ratio WIC/TNW) existed among habitat types (in parallel to differences in TNW). Thus, we constructed three different models with the same predictors and random variables yet subsequently using BIC, WIC and IS as response variables.

Second, we were interested in assessing the relationships between the different niche components (BIC, WIC and IS) and TNW across habitat types. To do this, we constructed a set of models subsequently using niche characteristics as response variables (BIC, WIC and IS). Taxa, body mass and the interaction between TNW and habitat type were the predictors, and study 
TABLE 1 | Differences in niche characteristics between habitats.

\begin{tabular}{|c|c|c|c|c|}
\hline \multicolumn{5}{|c|}{ TNW } \\
\hline${ }^{*}$ Fixed effects & Estimate & SE & $t$ & $P$ \\
\hline Intercept & 1.44 & 0.37 & 3.85 & $<0.01$ \\
\hline Natural - Rural & 0.34 & 0.33 & 1.02 & 0.31 \\
\hline Natural - Urban & 0.95 & 0.37 & 2.57 & 0.01 \\
\hline Rural - Urban & 0.61 & 0.33 & 1.85 & 0.06 \\
\hline Taxa & 0.72 & 0.57 & 1.26 & 0.21 \\
\hline Body mass & -0.04 & 0.02 & -2.54 & 0.01 \\
\hline${ }^{\star}$ Random effects & Variance & SD & & \\
\hline Location & 0.06 & 0.24 & & \\
\hline Species & 0.16 & 0.41 & & \\
\hline Residual & 0.19 & 0.44 & & \\
\hline \multicolumn{5}{|c|}{ WIC } \\
\hline${ }^{*}$ Fixed effects & Estimate & SE & $t$ & $\mathbf{P}$ \\
\hline Intercept & -0.84 & 0.59 & -1.43 & 0.15 \\
\hline Natural - Rural & 0.17 & 0.62 & 0.28 & 0.78 \\
\hline Natural - Urban & 0.81 & 0.65 & 1.26 & 0.21 \\
\hline Rural - Urban & 0.64 & 0.61 & 1.05 & 0.29 \\
\hline Taxa & -0.07 & 0.74 & -0.10 & 0.92 \\
\hline Body mass & -0.03 & 0.02 & -1.35 & 0.18 \\
\hline *Random effects & Variance & SD & & \\
\hline Location & 0.30 & 0.55 & & \\
\hline Species & $<0.01$ & $<0.01$ & & \\
\hline Residual & 0.74 & 0.86 & & \\
\hline \multicolumn{5}{|c|}{ BIC } \\
\hline${ }^{*}$ Fixed effects & Estimate & SE & $t$ & $\mathbf{P}$ \\
\hline Intercept & 0.67 & 0.31 & 2.20 & 0.03 \\
\hline Natural - Rural & 0.37 & 0.30 & 1.27 & 0.21 \\
\hline Natural - Urban & 0.60 & 0.32 & 1.89 & 0.06 \\
\hline Rural - Urban & 0.23 & 0.29 & 0.79 & 0.43 \\
\hline Taxa & 0.17 & 0.44 & 0.38 & 0.70 \\
\hline Body mass & -0.02 & 0.01 & -1.28 & 0.20 \\
\hline${ }^{\star}$ Random effects & Variance & SD & & \\
\hline Location & 0.07 & 0.26 & & \\
\hline Species & 0.07 & 0.26 & & \\
\hline Residual & 0.12 & 0.35 & & \\
\hline
\end{tabular}

\begin{tabular}{lrrrr}
\hline \multicolumn{4}{c}{ IS (WIC/TNW) } & \\
\hline *Fixed effects & Estimate & SE & t & P \\
\cline { 2 - 5 } & & & \\
Intercept & 0.61 & 0.16 & 3.73 & $<0.01$ \\
Natural - Rural & -0.10 & 0.18 & -0.55 & 0.58 \\
Natural - Urban & -0.06 & 0.18 & -0.33 & 0.74 \\
Rural - Urban & 0.04 & 0.17 & 0.23 & 0.82 \\
Taxa & 0.02 & 0.20 & 0.10 & 0.92 \\
Body mass & -0.01 & 0.01 & -1.11 & 0.27 \\
\hline
\end{tabular}

(Continued)
TABLE 1 | Continued

\begin{tabular}{lcc}
\hline & \multicolumn{2}{c}{ IS (WIC/TNW) } \\
\hline *Random effects & Variance & SD \\
\cline { 2 - 3 } & & \\
Location & 0.04 & 0.21 \\
Species & $<0.01$ & 0.05 \\
Residual & 0.02 & 0.16
\end{tabular}

Results from a set of linear mixed-effects models using Total Niche Width (TNW), its Within-Individual (WIC) and Between-Individual (BIC) Components, and Individual Specialization (IS = WIC/TNW) in 21 populations of birds and frogs as response variables. The predictors were habitat type (natural, rural or urban), taxa (birds or frogs) and body mass (g). Location (see Supplementary Material 1) and species (see Supplementary Material 2) were random factors. Significant effects are marked in bold letters. WIC values were log-transformed to approximate normality.

location and species were the random factors. Habitat type factor had three levels (natural, rural and urban), so that we dummy coded these factors and repeated the analysis using a different level as reference to ascertain all the possible combinations (e.g., natural vs. rural, rural vs. urban and natural vs. urban). Furthermore, there was considerable altitudinal variation among locations, and in spite that we have previously recorded negligible altitudinal effects on species' niche characteristics (Pagani-Núñez et al., 2019), we assessed whether it impacted individual level metrics. We recorded no significant effects of altitude on niche characteristics, so we excluded this variable from the final models (TNW: $P=0.37$, WIC: 0.11 , BIC: 0.81 , IS: 0.21 , data not shown).

We visually examined qqplots to confirm that model residuals were normally distributed. From the first set of models assessing differences in niche characteristics across habitat types, we found that the one using WIC as dependent variable did not fit this criterion. Thus, we repeated this model using log-transformed WIC values to approximate normality. We computed niche characteristics using the function WTcMC from the RInSp package (Zaccarelli et al., 2013) and constructed the linear mixed-effects models using the package lme4 v1.1-23 (Bates et al., 2015). All analyses were performed in R software v3.6.1 (R Core Team, 2017).

\section{RESULTS}

\section{Differences in TNW, WIC, BIC, and IS Across Habitat Types}

We found that frog and bird urban populations had larger TNWs than natural populations (Figure 4A and Table 1). Urban populations showed a non-significant tendency to display larger TNW than rural populations, while rural and natural populations showed no apparent differences in TNW (Table 1). We also found that TNW correlated negatively with body mass. Bird and frog populations did not show significant differences in WIC across habitat types (Figure 4B and Table 1). WIC and body mass were uncorrelated (Table 1).

Between-individual component of bird and frog urban populations showed a non-significant tendency to be larger than that of natural populations (Figure 4C and Table 1), while rural populations did not show significant differences 
with natural or urban populations. BIC and body mass were uncorrelated (Table 1).

We did not record any significant effect of habitat type or body mass on IS (WIC/TNW) (Table 1). Taxa showed no significant effects on niche characteristics (Table 1).

\section{Relationships Between TNW and WIC, $B I C$ and IS Within Habitat Types}

Within-individual component and TNW correlated positively in natural, rural and urban populations, the former showing the steepest curve (Figure 4D and Table 2). BIC showed a different pattern. BIC and TNW showed a strong positive correlation in both urban and rural populations but not in natural populations (Figure 4E). Finally, IS and TNW were uncorrelated across habitats (Table 2). Taxa and body mass showed no significant effects on these models (Table 2).

\section{DISCUSSION}

In this study, we illustrate how increases in population niche width (TNW) in birds and frogs showing different patterns across and within habitats. Within habitats, increases in TNW were a product of both increased niches within individuals (WIC), namely increased individual niche width, and increased distance between individuals (BIC), namely reduced overlap among individuals. These processes occurred simultaneously, thus, supporting our third hypothesis on individual niche dynamics across habitat transformation gradients (Figure 1). These positive relationships between TNW, WIC and BIC were rather persistent within habitats, with the exception of the relationship between TNW and BIC, which was not significant in natural habitats. Conversely, across habitats, although TNW increased markedly, we recorded no differences in WIC and only a weak tendency of BIC to increase from natural to urban habitats. Individual specialization (IS) showed no significant relationships with TNW across or within habitats. Hence, our results highlight how increases in TNW can be achieved by a combination of individual and population level niche changes, and is not invariably associated with an increase in IS.

\section{Differences in Niche Characteristics Across Habitat Types}

We found that species' niche expansion from natural to transformed habitats, namely increased TNW, did not necessarily imply dramatic changes in both WIC and BIC. While we did record markedly larger TNW in urban than in natural habitats, differences in WIC were negligible and species only showed a non-significant tendency to have larger BIC between these two habitat types. Many studies using different approaches have reported similar patterns of niche expansion across habitat transformation gradients (Bonier et al., 2007; Devictor et al., 2008a; Callaghan et al., 2019; Pagani-Núñez et al., 2019; Palacio, 2019), yet no study had thoroughly addressed how this pattern is a result of changes in different niche characteristics at the individual level. Our study is original in showing this pattern of trophic specialization within species, while previous
TABLE 2 | Relationships among niche characteristics within habitats.

\begin{tabular}{|c|c|c|c|c|}
\hline \multicolumn{5}{|c|}{ WIC } \\
\hline${ }^{*}$ Fixed effects & Estimate & SE & $t$ & $\mathbf{P}$ \\
\hline Intercept & 0.05 & 0.23 & 0.21 & 0.84 \\
\hline TNW: Natural & 0.62 & 0.26 & 2.42 & 0.02 \\
\hline TNW: Rural & 0.31 & 0.13 & 2.42 & 0.02 \\
\hline TNW: Urban & 0.41 & 0.11 & 3.91 & $<0.01$ \\
\hline Taxa & 0.08 & 0.24 & 0.34 & 0.73 \\
\hline Body mass & 0.00 & 0.01 & -0.44 & 0.66 \\
\hline *Random effects & Variance & SD & & \\
\hline Location & 0.02 & 0.15 & & \\
\hline Species & 0.02 & 0.13 & & \\
\hline Residual & 0.05 & 0.21 & & \\
\hline \multicolumn{5}{|c|}{$\mathrm{BIC}$} \\
\hline${ }^{*}$ Fixed effects & Estimate & SE & $\mathbf{t}$ & $\mathbf{P}$ \\
\hline Intercept & -0.05 & 0.23 & -0.21 & 0.84 \\
\hline TNW: Natural & 0.38 & 0.26 & 1.47 & 0.14 \\
\hline TNW: Rural & 0.69 & 0.13 & 5.32 & $<0.01$ \\
\hline TNW: Urban & 0.59 & 0.11 & 5.61 & $<0.01$ \\
\hline Taxa & -0.09 & 0.24 & -0.38 & 0.71 \\
\hline Body mass & $<0.01$ & 0.01 & 0.47 & 0.64 \\
\hline *Random effects & Variance & SD & & \\
\hline Location & 0.02 & 0.14 & & \\
\hline Species & 0.02 & 0.12 & & \\
\hline Residual & 0.05 & 0.22 & & \\
\hline
\end{tabular}

\begin{tabular}{lcccr}
\hline & \multicolumn{2}{c}{ IS (WIC/TNW) } & & \\
\hline *Fixed effects & Estimate & SE & t & P \\
\cline { 2 - 4 } Intercept & 0.60 & 0.18 & 3.38 & $<0.01$ \\
TNW: Natural & 0.14 & 0.23 & 0.63 & 0.53 \\
TNW: Rural & -0.12 & 0.10 & -1.25 & 0.21 \\
TNW: Urban & -0.02 & 0.09 & -0.20 & 0.84 \\
Taxa & -0.02 & 0.19 & -0.09 & 0.93 \\
Body mass & -0.01 & 0.01 & -1.12 & 0.26 \\
\cline { 2 - 4 } *Random effects & Variance & SD & & \\
\cline { 2 - 4 } & 0.04 & 0.20 & & \\
Location & $<0.01$ & 0.05 & & \\
Species & 0.02 & 0.15 & & \\
Residual & & & & \\
\end{tabular}

Results from a set of linear mixed-effects models using the Within-Individual (WIC) and Between-Individual (BIC) niche components, and Individual Specialization $(I S=$ WIC/TNW $)$ in 21 populations of birds and frogs as response variables. The predictors were the interaction between Total Niche Width (TNW) and habitat type (natural, rural or urban), taxa (birds or frogs) and body mass (g). Location (see Supplementary Material 1) and species (see Supplementary Material 2) were random factors. Significant effects are marked in bold letters.

studies analyzing changes in specialization mostly focused on interspecific comparisons in habitat use (Julliard et al., 2006; Devictor et al., 2008b; Rivas-Salvador et al., 2019). Nevertheless, 
having a clear idea of what happens to individuals is fundamental to avoid biased estimations of species- or population-level estimation of isotopic niches (Flaherty and Ben-David, 2010).

Larger TNWs could be a product of urban individuals showing high behavioral innovativeness typical of generalist species (Ducatez et al., 2015; Sol et al., 2016; Griffin et al., 2017), having broad available empty niches (Sanz-Aguilar et al., 2015; Yurkowski et al., 2016; Balme et al., 2019), or a combination of both processes. However, since BIC increased more than WIC across the transformation gradients, our results suggest therefore that habitat heterogeneity would be the main facilitator of niche expansion -promoting lower overlap among individuals within each species (Darimont et al., 2009; Newsome et al., 2015). We cannot discard that changes in aggressiveness toward conspecifics across habitats may have influenced BIC values too.

\section{Differences in the Relationships Between Niche Characteristics Within Habitat Types}

We recorded different relationships among niche characteristics within habitat types. A positive relationship between TNW and WIC was apparent in natural, rural and urban habitats. We also recorded strong positive relationships between TNW and BIC in rural and urban habitats, but not in natural habitats. Both WIC and BIC facilitated niche expansion (Figure 1), and our results showed that increased distance among individuals, i.e., BICs or decreased inter-individual niche overlap, was only possible in transformed habitats, where population niches (TNWs) were large enough to allow this process to occur, supporting the idea that increasing habitat heterogeneity may have facilitated niche expansion across the transformation gradient.

In contrast with previous studies using a diverse array of statistical approaches (Newsome et al., 2015; Navarro et al., 2017; Murray et al., 2018), we recorded no significant relationships between TNW expansion and individual specialization (IS). Traditionally, the niche variation hypothesis suggests that increases in niche width (TNW in our case) are mainly achieved as a main consequence of a parallel increase in IS (Ebenman and Nilsson, 1982; Dayan and Simberloff, 1994; Bolnick et al., 2007; Cachera et al., 2017; Maldonado et al., 2017). Conversely, our study suggests that WIC, and especially BIC, are predominantly associated with increases in TNW. We recorded this pattern using two rather different taxonomic groups, birds and frogs, which suggests that this fashion may be common throughout vertebrates.

\section{CONCLUSION}

Generally, research investigating the consequences of habitat transformation for niche characteristics of species and populations (and, therefore, community assemblage dynamics) focus on broad scale processes (Darimont et al., 2009; Quevedo et al., 2009; Newbold et al., 2018; Sol et al., 2020). Thus, it remains unclear how individuals respond to these changes at finer scales. In other words, environmental generalists have broad niches and are able to colonize many habitat types but, so far, it was unclear how their individual niches were configured (Ducatez et al., 2018). Our research is important in linking populationlevel niche processes to individual-level niche characteristics. Although we may acknowledge that our sample size was rather limited and we were pooling different taxa (birds and frogs), our findings overturn traditional conceptions on the mechanisms and consequences of niche expansion, illustrating diverse ways in which it can be achieved. Further research could ascertain to what extent individual-level niche characteristics of transformed habitats are a consequence of individuals being generally more innovative and thus exploiting a broad variety of food and habitat resources or whether they merely reflect a particular habitat structure that enables individuals having broad niches without overlapping with conspecifics (Ducatez et al., 2015).

\section{DATA AVAILABILITY STATEMENT}

The datasets presented in this study can be found in online repositories. The names of the repository/repositories and accession number(s) can be found below: NCBI (https://www. ncbi.nlm.nih.gov/) MT940544-MT940569 (26 16S sequences) and MT941534-MT941565 (32 ND2 sequences).

\section{ETHICS STATEMENT}

The animal study was reviewed and approved by Animal Care Committee of CIB, CAS and Guangxi Forestry Bureau.

\section{AUTHOR CONTRIBUTIONS}

EP-N, YL, JH, DL, SY, and EG conceived and designed the study. EP-N, CH, DL, and SY performed the study and collected the data with assistance from YL, JH, and WL. EP-N, SY, and DL analyzed the data and wrote the draft of the manuscript with input from all authors.

\section{FUNDING}

This study was funded by the 1000 Plan Recruitment Program of Global Experts from the People's Republic of China to EG, and the National Natural Science Foundation of China (31770568 and 31572290), the 'Light of West China' Program of the Chinese Academy of Sciences (2019XBZG_XBQNZG_A_003) to JH, the Special Talent Recruitment Program of Guangxi University (GXU) to EG, the Postdoctoral Research Fund of GXU to EP-N, and the Fundamental Research Funds for the Central Universities (161gpy34) to YL.

\section{ACKNOWLEDGMENTS}

We thank Craig A. Barnett, Demeng Jiang, Ruchuan He, Indika Peabotuwage, Xu Luo, Ge Gao, Wande Li, Guansheng Wang, Qiang Yang, Xinyuan Pan, Xuejing Wang, Binqiang Li, Xue Gou, and Chunpeng Guo for their help in the field. We are very 
grateful to the Forestry Bureau of Guangxi Zhuang Autonomous Region, to the managers of Damingshan National Reserve, Gaoligongshan National Reserve, Longshan Regional Reserve, Medicinal Botanical Garden of Nanning and Gaofeng National Forest Park for providing permissions.

\section{REFERENCES}

Araújo, M. S., Bolnick, D. I., and Layman, C. A. (2011). The ecological causes of individual specialisation: the causes of individual specialisation. Ecol. Lett. 14, 948-958. doi: 10.1111/j.1461-0248.2011.01662.x

Araújo, M. S., Bolnick, D. I., Martinelli, L. A., Giaretta, A. A., and Dos Reis, S. F. (2009). Individual-level diet variation in four species of Brazilian frogs. J. Anim. Ecol. 78, 848-856. doi: 10.1111/j.1365-2656.2009.01546.x

Balme, G. A., le Roex, N., Rogan, M. S., and Hunter, L. T. B. (2019). Ecological opportunity drives individual dietary specialisation in leopards. J. Anim. Ecol. 89, 589-600. doi: 10.1111/1365-2656.13109

Bates, D., Mächler, M., Bolker, B., and Walker, S. (2015). Fitting linear mixed-effects models using lme4. J. Stat. Softw. 67, 1-48. doi: 10.18637/jss.v067.i01

Bearhop, S., Furness, R. W., Hilton, G. M., Votier, S. C., and Waldron, S. (2003). A forensic approach to understanding diet and habitat use from stable isotope analysis of (avian) claw material. Funct. Ecol. 17, 270-275. doi: 10.1046/j.13652435.2003.00725.x

Boecklen, W. J., Yarnes, C. T., Cook, B. A., and James, A. C. (2011). On the use of stable isotopes in trophic ecology. Annu. Rev. Ecol. Evol. Syst. 42, 411-440. doi: 10.1146/annurev-ecolsys-102209-144726

Bolnick, D. I., Svanback, R., Araujo, M. S., and Persson, L. (2007). Comparative support for the niche variation hypothesis that more generalized populations also are more heterogeneous. Proc. Natl. Acad. Sci. U.S.A. 104, 10075-10079. doi: 10.1073/pnas.0703743104

Bolnick, D. I., Svanbäck, R., Fordyce, J. A., Yang, L. H., Davis, J. M., Hulsey, C. D., et al. (2003). The ecology of individuals: incidence and implications of individual specialization. Am. Nat. 161, 1-28. doi: 10.1086/343878

Bond, A. L., Jardine, T. D., and Hobson, K. A. (2016). Multi-tissue stable-isotope analyses can identify dietary specialization. Methods Ecol. Evol. 7, 1428-1437. doi: 10.1111/2041-210X.12620

Bonier, F., Martin, P. R., and Wingfield, J. C. (2007). Urban birds have broader environmental tolerance. Biol. Lett. 3, 670-673. doi: 10.1098/rsbl.2007. 0349

Cachera, M., Ernande, B., Villanueva, M. C., and Lefebvre, S. (2017). Individual diet variation in a marine fish assemblage: optimal foraging theory, niche variation hypothesis and functional identity. J. Sea Res. 120, 60-71. doi: 10.1016/j.seares. 2016.08.004

Callaghan, C. T., Major, R. E., Wilshire, J. H., Martin, J. M., Kingsford, R. T., and Cornwell, W. K. (2019). Generalists are the most urban-tolerant of birds: a phylogenetically controlled analysis of ecological and life history traits using a novel continuous measure of bird responses to urbanization. Oikos 128, 845-858. doi: 10.1111/oik.06158

Clavel, J., Julliard, R., and Devictor, V. (2011). Worldwide decline of specialist species: toward a global functional homogenization? Front. Ecol. Environ. 9, 222-228. doi: 10.1890/080216

Coogan, S. C. P., Raubenheimer, D., Zantis, S. P., and Machovsky-Capuska, G. E. (2018). Multidimensional nutritional ecology and urban birds. Ecosphere 9:e02177. doi: 10.1002/ecs2.2177

Darimont, C. T., Paquet, P. C., and Reimchen, T. E. (2009). Landscape heterogeneity and marine subsidy generate extensive intrapopulation niche diversity in a large terrestrial vertebrate. J. Anim. Ecol. 78, 126-133. doi: 10. 1111/j.1365-2656.2008.01473.x

Dayan, T., and Simberloff, D. (1994). Character displacement, sexual dimprphism, and morphological variation among British and Irish mustelids. Ecology 75, 1063-1073. doi: 10.2307/1939430

Dayananda, S. K., Mammides, C., Lee, M. B., Liu, J. J., Pasion, B. O., Sreekar, R., et al. (2017). Topography and soil type are critical to understanding how bird and herpetofaunal communities persist in forest fragments of tropical China. Biol. Conserv. 215, 107-115. doi: 10.1016/j.biocon.2017.08.034

\section{SUPPLEMENTARY MATERIAL}

The Supplementary Material for this article can be found online at: https://www.frontiersin.org/articles/10.3389/fevo.2020. 597450/full\#supplementary-material

Devictor, V., Julliard, R., Clavel, J., Jiguet, F., Lee, A., and Couvet, D. (2008a). Functional biotic homogenization of bird communities in disturbed landscapes. Glob. Ecol. Biogeogr. 17, 252-261. doi: 10.1111/j.1466-8238.2007.00364.x

Devictor, V., Julliard, R., and Jiguet, F. (2008b). Distribution of specialist and generalist species along spatial gradients of habitat disturbance and fragmentation. Oikos 117, 507-514. doi: 10.1111/j.2008.0030-1299.16215.x

Ducatez, S., Clavel, J., and Lefebvre, L. (2015). Ecological generalism and behavioural innovation in birds: technical intelligence or the simple incorporation of new foods? J. Anim. Ecol. 84, 79-89. doi: 10.1111/1365-2656. 12255

Ducatez, S., Sayol, F., Sol, D., and Lefebvre, L. (2018). Are urban vertebrates city specialists, artificial habitat exploiters, or environmental generalists? Integr. Comp. Biol. 58, 929-938. doi: 10.1093/icb/icy101

Ebenman, B., and Nilsson, S. G. (1982). Components of niche width in a territorial bird species: habitat utilization in males and females of the chaffinch (Fringilla coelebs) on islands and mainland. Am. Nat. 119, 331-344. doi: 10.1086/283913

Fei, L., Hu, S., Ye, C., and Huang, Y. (2009). Fauna Sinica. Amphibia. Vol. 3. Anura Ranidae. Beijing: Science Press.

Figgener, C., Bernardo, J., and Plotkin, P. T. (2019). Beyond trophic morphology: stable isotopes reveal ubiquitous versatility in marine turtle trophic ecology. Biol. Rev. Camb. Philos. Soc. 94, 1947-1973. doi: 10.1111/brv.12543

Flaherty, E. A., and Ben-David, M. (2010). Overlap and partitioning of the ecological and isotopic niches. Oikos 119, 1409-1416. doi: 10.1111/j.1600-0706. 2010.18259.x

Flynn, D. F. B., Gogol-Prokurat, M., Nogeire, T., Molinari, N., Richers, B. T., Lin, B. B., et al. (2009). Loss of functional diversity under land use intensification across multiple taxa. Ecol. Lett. 12, 22-33. doi: 10.1111/j.1461-0248.2008. 01255.x

Griffin, A. S., Netto, K., and Peneaux, C. (2017). Neophilia, innovation and learning in an urbanized world: a critical evaluation of mixed findings. Curr. Opin. Behav. Sci. 16, 15-22. doi: 10.1016/j.cobeha.2017.01.004

Hahn, S., Dimitrov, D., Rehse, S., Yohannes, E., and Jenni, L. (2014). Avian claw morphometry and growth determine the temporal pattern of archived stable isotopes. J. Avian Biol. 45, 202-207. doi: 10.1111/j.1600-048X.2013.00324.x

Herrera-Montes, M. I., and Aide, T. M. (2011). Impacts of traffic noise on anuran and bird communities. Urban Ecosyst. 14, 415-427. doi: 10.1007/s11252-0110158-7

$\mathrm{Hu}, \mathrm{J}$. , and Jiang, J. (2018). Inferring ecological explanations for biogeographic boundaries of parapatric Asian mountain frogs. BMC Ecol. 18:3. doi: 10.1186/ s12898-018-0160-5

Huang, Y., Wang, X., Yang, X., Jiang, J., and Hu, J. (2020). Unveiling the roles of interspecific competition and local adaptation in phenotypic differentiation of parapatric frogs. Curr. Zool. 66, 383-392. doi: 10.1093/cz/zoaa001

Inger, R., and Bearhop, S. (2008). Applications of stable isotope analyses to avian ecology. IBIS 150, 447-461. doi: 10.1111/j.1474-919X.2008.00839.x

Julliard, R., Clavel, J., Devictor, V., Jiguet, F., and Couvet, D. (2006). Spatial segregation of specialists and generalists in bird communities. Ecol. Lett. 9, 1237-1244. doi: 10.1111/j.1461-0248.2006.00977.x

Layman, C. A., Araujo, M. S., Boucek, R., Hammerschlag-Peyer, C. M., Harrison, E., Jud, Z. R., et al. (2012). Applying stable isotopes to examine food-web structure: an overview of analytical tools. Biol. Rev. 87, 545-562. doi: 10.1111/j.1469-185X. 2011.00208.x

Layman, C. A., Newsome, S. D., and Gancos Crawford, T. (2015). Individual-level niche specialization within populations: emerging areas of study. Oecologia 178, 1-4. doi: 10.1007/s00442-014-3209-y

Liang, D., He, C., Luo, X., Liu, Y., Goodale, E., and Pagani-Núñez, E. (2018). Breath rate of passerines across an urbanization gradient supports the paceof-life hypothesis and suggests diet-mediated responses to handling stress. Ecol. Evol. 8, 9526-9535. doi: 10.1002/ece3.4460 
Liu, J., Viña, A., Yang, W., Li, S., Xu, W., and Zheng, H. (2018). China’s environment on a metacoupled planet. Annu. Rev. Environ. Resour. 43, 1-34. doi: 10.1146/ annurev-environ-102017-030040

Maldonado, K., Bozinovic, F., Newsome, S. D., and Sabat, P. (2017). Testing the niche variation hypothesis in a community of passerine birds. Ecology 98, 903-908. doi: 10.1002/ecy.1769

Matsubayashi, J., Saitoh, Y., Osada, Y., Uehara, Y., Habu, J., Sasaki, T., et al. (2017). Incremental analysis of vertebral centra can reconstruct the stable isotope chronology of teleost fishes. Methods Ecol. Evol. 8, 1755-1763. doi: 10.1111/ 2041-210X.12834

McKinney, M. L. (2008). Effects of urbanization on species richness: a review of plants and animals. Urban Ecosyst. 11, 161-176. doi: 10.1007/s11252-0070045-4

Meiri, S., Dayan, T., and Simberloff, D. (2005). Variability and sexual size dimorphism in carnivores: testing the niche variation hypothesis. Ecology 86, 1432-1440. doi: 10.1890/04-1503

Murray, M. H., Kidd, A. D., Curry, S. E., Hepinstall-Cymerman, J., Yabsley, M. J., Adams, H. C., et al. (2018). From wetland specialist to hand-fed generalist: shifts in diet and condition with provisioning for a recently urbanized wading bird. Philos. Trans. R. Soc. Lond. B Biol. Sci. 373:20170100. doi: 10.1098/rstb.2017. 0100

Navarro, J., Grémillet, D., Ramirez, F., Afán, I., Bouten, W., and Forero, M. (2017). Shifting individual habitat specialization of a successful predator living in anthropogenic landscapes. Mar. Ecol. Prog. Ser. 578, 243-251. doi: 10.3354/ meps 12124

Newbold, T., Hudson, L. N., Contu, S., Hill, S. L. L., Beck, J., Liu, Y., et al. (2018). Widespread winners and narrow-ranged losers: land use homogenizes biodiversity in local assemblages worldwide. PLoS Biol. 16:e2006841. doi: 10. 1371/journal.pbio.2006841

Newbold, T., Hudson, L. N., Hill, S. L. L., Contu, S., Lysenko, I., Senior, R. A., et al. (2015). Global effects of land use on local terrestrial biodiversity. Nature 520, 45-50. doi: 10.1038/nature14324

Newsome, S. D., Tinker, M. T., Gill, V. A., Hoyt, Z. N., Doroff, A., Nichol, L., et al. (2015). The interaction of intraspecific competition and habitat on individual diet specialization: a near range-wide examination of sea otters. Oecologia 178, 45-59. doi: 10.1007/s00442-015-3223-8

Pagani-Núñez, E., Liang, D., He, C., Zhou, X., Luo, X., Liu, Y., et al. (2019). Niches in the anthropocene: passerine assemblages show niche expansion from natural to urban habitats. Ecography 42, 1360-1369. doi: 10.1111/ecog.04203

Pagani-Núñez, E., Valls, M., and Senar, J. C. (2015). Diet specialization in a generalist population: the case of breeding great tits Parus major in the Mediterranean area. Oecologia 179, 629-640. doi: 10.1007/s00442-015-3334-2

Palacio, F. X. (2019). Urban exploiters have broader dietary niches than urban avoiders. IBIS 162, 42-49. doi: 10.1111/ibi.12732

Quevedo, M., Svanbäck, R., and Eklöv, P. (2009). Intrapopulation niche partitioning in a generalist predator limits food web connectivity. Ecology 90, 2263-2274. doi: 10.1890/07-1580.1

R Core Team. (2017). R: A Language and Environment for Statistical Computing. Available online at: https://www.R-project.org/

Rivas-Salvador, J., Hořák, D., and Reif, J. (2019). Spatial patterns in habitat specialization of European bird communities. Ecol. Indic. 105, 57-69. doi: 10. 1016/j.ecolind.2019.05.063

Roughgarden, J. (1972). Evolution of niche width. Am. Nat. 106, 683-718. doi: $10.1086 / 282807$

Roughgarden, J. (1974). Niche width: biogeographic patterns among Anolis lizard populations. Am Nat. 108, 429-442. doi: 10.1086/282924
Sanz-Aguilar, A., Carrete, M., Edelaar, P., Potti, J., and Tella, J. L. (2015). The empty temporal niche: breeding phenology differs between coexisting native and invasive birds. Biol. Invasions 17, 3275-3288. doi: 10.1007/s10530-015-0952-x

Seto, K. C., Fragkias, M., Güneralp, B., and Reilly, M. K. (2011). A meta-analysis of global urban land expansion. PLoS One 6:e23777. doi: 10.1371/journal.pone. 0023777

Simberloff, D., Dayan, T., Jones, C., and Ogura, G. (2000). Character displacement and release in the small Indian mongoose, Herpestes javanicus. Ecology 81, 2086-2099. doi: 10.2307/177098

Smith, R. L., Beard, K. H., and Shiels, A. B. (2017). Different prey resources suggest little competition between non-native frogs and insectivorous birds despite isotopic niche overlap. Biol. Invasions 19, 1001-1013. doi: 10.1007/s10530-0161333-9

Sol, D., Lapiedra, O., and González-Lagos, C. (2013). Behavioural adjustments for a life in the city. Anim. Behav. 85, 1101-1112. doi: 10.1016/j.anbehav.2013.01.023

Sol, D., Sayol, F., Ducatez, S., and Lefebvre, L. (2016). The life-history basis of behavioural innovations. Philos. Trans. R. Soc. Lond. B Biol. Sci. 371:20150187. doi: 10.1098/rstb.2015.0187

Sol, D., Trisos, C., Múrria, C., Jeliazkov, A., González-Lagos, C., Pigot, A. L., et al. (2020). The worldwide impact of urbanisation on avian functional diversity: urbanisation and avian functional diversity. Ecol. Lett. 23, 962-972. doi: 10. 1111/ele.13495

Van Valen, L. (1965). Morphological variation and width of ecological niche. Am. Nat. 99, 377-390. doi: 10.1086/282379

Vander Zanden, M. J., Clayton, M. K., Moody, E. K., Solomon, C. T., and Weidel, B. C. (2015). Stable isotope turnover and half-life in animal tissues: a literature synthesis. PLoS One 10:e0116182. doi: 10.1371/journal.pone.0116182

Vergnon, R., Dulvy, N. K., and Freckleton, R. P. (2009). Niches versus neutrality: uncovering the drivers of diversity in a species-rich community. Ecol. Lett. 12, 1079-1090. doi: 10.1111/j.1461-0248.2009.01364.x

Wang, X., Huang, Y., Zhong, M., Yang, S., Yang, X., Jiang, J., et al. (2019). Environmental stress shapes life-history variation in the swelled-vented frog (Feirana quadranus). Evol. Ecol. 33, 435-448. doi: 10.1007/s10682-019-09980-5

Yang, X., Wang, B., Hu, J., and Jiang, J. (2011). A new species of the genus Feirana (Amphibia: Anura: Dicroglossidae) from the Western Qinling Mountains of China. Asian Herpetol. Res. 2, 72-86. doi: 10.3724/SP.J.1245.2011.00072

Yurkowski, D. J., Ferguson, S., Choy, E. S., Loseto, L. L., Brown, T. M., Muir, D. C. G., et al. (2016). Latitudinal variation in ecological opportunity and intraspecific competition indicates differences in niche variability and diet specialization of Arctic marine predators. Ecol. Evol. 6, 1666-1678. doi: 10.1002/ ece3.1980

Zaccarelli, N., Bolnick, D. I., and Mancinelli, G. (2013). RInSp: an R-package for the analysis of individual specialization in resource use. Methods Ecol. Evol. 4, 1018-1023. doi: 10.1111/2041-210X.12079

Conflict of Interest: The authors declare that the research was conducted in the absence of any commercial or financial relationships that could be construed as a potential conflict of interest.

Copyright (c) 2020 Liang, Yang, Pagani-Núñez, He, Liu, Goodale, Liao and Hu. This is an open-access article distributed under the terms of the Creative Commons Attribution License (CC BY). The use, distribution or reproduction in other forums is permitted, provided the original author(s) and the copyright owner(s) are credited and that the original publication in this journal is cited, in accordance with accepted academic practice. No use, distribution or reproduction is permitted which does not comply with these terms. 